\title{
PROBLEMATIZANDO A PESQUISA LINGUÍSTICA SOBRE ENSINO DA PRODUÇÃO TEXTUAL POR MEIO DE GÊNEROS
}

\author{
Luiz Eduardo Mendes Batista* \\ Maura Alves Freitas Rocha*
}

\begin{abstract}
RESUMO: Este artigo objetiva analisar as principais escolhas teórico-metodológicas efetuadas por estudiosos da linguística brasileira, especialmente por aqueles interessados por um ensino de produção textual oral e escrita que elege os gêneros discursivos como objeto central. Para isso, coletamos e analisados todos os artigos sobre esse tema publicados nos anais do Simpósio Internacional de Ensino de Língua Portuguesa (SIELP) em suas edições brasileiras. Observamos que, embora haja esforços no sentido de se reconhecer a ideia de gêneros discursivos na esfera escolar como efetivo objeto de inserção do aluno em práticas sociais em atendimento às demandas contemporâneas, há muitas confusões e problemas relativos principalmente às escolhas metodológicas efetuadas.
\end{abstract}

PALAVRAS-CHAVE: Pesquisa linguística; Gêneros discursivos; Ensino da produção textual; Educação Básica brasileira.

A efervescência provocada nos meios acadêmicos quando da publicação dos Parâmetros Curriculares Nacionais (PCN) (BRASIL, 1998), no fim do século passado, deveuse de modo especial à emergência das propostas de se tomarem os gêneros discursivos como objeto central de ensino de língua capaz de, finalmente, ancorar esse ensino às práticas sociais de linguagem. Hoje, vinte anos após a publicação desse documento, em resposta à euforia inicial, considerada por muitos como um "modismo", a pesquisa sobre

\footnotetext{
* Doutorando em Estudos Linguísticos pela Universidade Federal de Uberlândia (Ufu). Membro do Centro de Pesquisa em Ensino de Língua Portuguesa da mesma Universidade (CEPELP/Ufu).

${ }^{* *}$ Doutora em Linguística pela Universidade Estadual de Campinas (Unicamp). Professora do Programa de PósGraduação em Estudos Linguísticos da Universidade Federal de Uberlândia (Ufu). Coordenadora do Centro de Pesquisas de Ensino de Língua Portuguesa (CEPELP/Ufu).
} 
ensino de gêneros na escolaridade básica brasileira parece ter ganhado - ou está ganhando - certa sobriedade.

Esse contexto da pesquisa sobre gêneros, que vem adquirindo novos significados com a presença indelével dos novos letramentos digitais na escola e com crescentes demandas por melhores condições de aprendizagem da produção de textos orais e escritos, nos leva ao principal objetivo deste trabalho que trata de investigar e discutir os rumos tomados pela pesquisa brasileira no que concerne ao trabalho com gêneros discursivos na escola. Mais especificamente, tratamos de investigar tendências e diretrizes tomadas pela pesquisa linguística aplicada no Brasil em relação aos processos de produção de textos orais e escritos na Educação Básica.

Não negamos que a recente publicação da Base Nacional Comum Curricular (BNCC) (BRASIL, 2017) poderia ter-nos motivado em certo sentido neste trabalho, especialmente porque, a nosso ver, esse documento, além de representar mais continuidades que rupturas em relação aos $\mathrm{PCN}^{4}$, reafirma a centralidade dos gêneros discursivos/ textuais no processo de aprendizagem da língua. No entanto, nossa referência principal precisou ser os PCN, principalmente pelo fato de que o distanciamento temporal de duas décadas de sua publicação nos permite um olhar mais atento para as recorrências a este documento em termos de pesquisa acadêmica sobre o assunto.

Para atingir nosso objetivo principal, elegemos os anais do Simpósio Internacional de Língua Portuguesa ${ }^{5}$ (SIELP) em suas edições realizadas no Brasil pela Universidade Federal de Uberlândia, em Minas Gerais. Tendo surgido em 2011, o SIELP estabelece com Portugal diálogos importantes sobre o ensino de língua portuguesa e, de lá para cá, tem agregado um número crescente de pesquisadores de diversas universidades luso-brasileiras. Realizado em alternância entre os dois países, no Brasil, as edições do SIELP ocorreram

\footnotetext{
${ }^{4}$ Em Batista (2018), realizamos uma discussão sobre as abordagens do conceito de gêneros textuais/discursivos nos PCN e na BNCC.

5 Todo o corpus deste artigo pode ser encontrado no site do evento que, em novembro deste ano, realizará sua

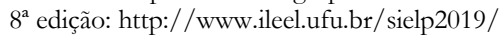


em 2011, 2012, 2014 e 2016, períodos, portanto, em que nossa investigação se concentra. Concordamos com Bawarshi e Reiff (2013) que a pesquisa brasileira sobre gêneros ganhou dinamicidade com as realizações, desde 2003, do Simpósio Internacional de Estudos de Gêneros Textuais (SIGET). Entretanto, para este estudo, nossa escolha pelos artigos publicados nos anais do SIELP se deu principalmente porque este Simpósio congregou, e vem congregando, trabalhos que giram em torno especificamente do "ensino" de língua, foco de nossas atenções. Assim sendo, poderíamos dizer que, em certa medida, o SIELP tem sido um espaço "catalisador" das principais tendências sobre o tema.

Diante desses elementos, fomos aos artigos com algumas questões que nortearão os próximos itens, a saber:

a) Quais concepções teóricas fundamentam as pesquisas sobre ensino de produção de texto por meio de gêneros discursivos/textuais? Há implicações terminológicas a partir dessas escolhas?

b) A quais suportes metodológicos os pesquisadores recorrem ao tratarem desse ensino?

c) Quais os possíveis alcances e limitações dessas escolhas teórico-metodológicas?

Antes de passarmos às reflexões sobre essas questões, exporemos alguns dados inicialmente observados em nosso corpus referentes ao crescente interesse pela pesquisa sobre ensino de produção textual por meio de gêneros, como mostra a tabela abaixo.

Tabela 1. Percentual de trabalhos sobre produção textual por meio de gêneros publicados nos anais das quatro edições do SIELP

\begin{tabular}{cccc}
\hline Edição & $\begin{array}{c}\text { Total de artigos publicados } \\
\text { (temas diversos) }\end{array}$ & $\begin{array}{l}\text { Total de artigos sobre produção } \\
\text { textual por meio de gêneros }\end{array}$ & $\begin{array}{l}\text { Percen- } \\
\text { tual }\end{array}$ \\
\hline 2011 & 97 & 1 & $1 \%$ \\
2012 & 291 & 12 & $4 \%$ \\
2014 & 244 & 13 & $5,3 \%$ \\
2016 & 147 & 16 & $10,8 \%$ \\
\hline
\end{tabular}

Fonte: os autores. 
O crescente número de pesquisas sobre produção textual por meio de gêneros discursivos remete ao interesse que o assunto vem ganhando ao longo dos anos e, se considerarmos que o SIELP aceita trabalhos publicados em várias vertentes do ensino de língua portuguesa, além de outras áreas como ensino de literatura e de línguas estrangeiras, o percentual de 2016, 10,8\%, é bem representativo.

\section{Das escolhas teóricas}

Considerando que os Parâmetros Curriculares Nacionais sejam o documento basilar e que, em relação ao ensino de língua materna, norteou nesses últimos vinte anos em grande medida as pesquisas sobre o tema no Brasil, como dissemos acima, não é novidade afirmar que a maioria dos estudiosos se aproximam de vertentes teóricas como o Interacionismo Socio-discursivo (ISD), como definido a priori por Jean-Paul Bronckart, e dos estudos sobre didática de língua materna, sob influência sobretudo de autores suíços como Joaquim Dolz e Bernard Schneuwly. As concepções sobre ensino de língua materna desses autores, vale reforçar, permeiam todo o documento. Para dialogar com esses teóricos, os pesquisadores brasileiros recorrem ainda a autores da Linguística Textual desenvolvida no Brasil, principalmente filiados às pesquisas de Luiz Antônio Marcuschi e Ingedore Koch. A aproximação é compreensível, dentre outras razões, porque os autores suíços se utilizam dos conceitos e instrumentos da Linguística de Texto, com suas devidas adaptações, para explorarem noções como sequência textual, tipologia, superestrutura, macro/microestrutura coesão, coerência. Por isso, predominam-se nesses trabalhos o uso do termo "gêneros textuais", em detrimento de "gêneros discursivos", refratando esta noção fundamentada a priori em Bakhtin (2016).

Assim, dos 42 artigos publicados nos anais do SIELP em suas quatro edições brasileiras sobre o tema que estamos priorizando aqui, apenas 5 não referenciam diretamente a perspectiva teórica acima. Isso significa que em torno de $88 \%$ dos trabalhos partem das concepções de "gênero textual", enquanto 12\% dos trabalhos "fogem à regra". Estes últimos estão distribuídos da seguinte forma: 
- Dois, dos cinco trabalhos, se utilizam principalmente das conceituações bakhtinianas para explorarem o ensino da produção textual por meio de gêneros na escola. Em um dos casos, faz referência a autores brasileiros como Adail Sobral e João W. Geraldi;

- Outros dois trabalhos fazem referência à perspectiva sociorretórica de gêneros, principalmente como definido por John Swales e Charles Bazerman, para explorar, por exemplo, a Estrutura Potencial do Gênero. Um dos trabalhos ainda busca dialogar com a visão dos estudiosos de Genebra;

- Apenas um trabalho faz referência à teoria da enunciação de Émile Benveniste, especialmente ao conceito de subjetividade na produção escrita do aluno.

Além de confirmarmos a predominância da perspectiva teórica que toma os mecanismos de textualidade como princípio de investigação científica, buscamos verificar como se dá a distribuição dos trabalhos entre ensino de produção oral e escrita na escola ao longo das edições do SIELP e chegamos à seguinte síntese:

Tabela 2. Percentual de pesquisas sobre as modalidades oral e escrita no ensino de produção textual por meio de gêneros

\begin{tabular}{cccc}
\hline Edição & $\begin{array}{c}\text { Produção textual ESCRITA } \\
\text { (total/percentual) }\end{array}$ & $\begin{array}{c}\text { Produção textual ORAL } \\
\text { (total/percentual) }\end{array}$ & $\begin{array}{c}\text { Indiferente } \\
\text { (total/ } \\
\text { percentual) }\end{array}$ \\
\hline 2011 & $1 / 100 \%$ & 0 & 0 \\
2012 & $9 / 75 \%$ & $2 / 17 \%$ & $1 / 8 \%$ \\
2014 & $12 / 92 \%$ & $1 / 8 \%$ & 0 \\
2016 & $13 / 81 \%$ & $3 / 19 \%$ & 0 \\
\hline
\end{tabular}

Fonte: os autores.

Como se vê, há predominância do ensino da modalidade escrita sobre a oral no processo de ensino de produção textual. Uma das novidades dos PCN foi o fato de tratar 
o oral como objeto de ensino, especialmente aquele oral produzido em situações formais de comunicação. No entanto, não é o que se tem observado nas pesquisas sobre o assunto. Mesmo tendo havido um aumento em 2016 de pesquisas em que os gêneros orais aparecem como relevantes, ainda é ínfimo em relação aos estudos sobre ensino da escrita. O item "indiferente" diz respeito àquelas pesquisas em que o estudioso não tinha prioridade sobre uma modalidade ou outra.

\section{Gênero textual ou gênero discursivo: ainda faz sentido "diferenciar"?}

Diante de todas essas observações, não podemos nos furtar a uma questão que, vez ou outra, ressurge e reacende os debates nos meios acadêmicos, ou seja, é pertinente ou não diferenciar as nomenclaturas "gênero textual" e "gênero discursivo"? Para nós, especialmente quando falamos em pesquisa acadêmica, a resposta é sim. Se no período da publicação de Rojo (2005) os trabalhos acadêmicos já mostravam certos pontos de vista que alteravam o modo de conceber o objeto em questão, hoje, não temos dúvidas de que se faz necessária a escolha por um ou outro termo. As principais razões já foram colocadas pela autora mencionada e dizem respeito basicamente à aproximação ou ao distanciamento das ideias de Mikhail Bakhtin sobre o que esse autor considera por "gêneros do discurso".

Desse modo, quando uma pesquisa empreende um olhar mais acurado para as esferas de circulação dos gêneros, intentando compreender as bordas sociais de circulação de determinado gênero e o modo como esse aspecto age sobre o funcionamento do gênero, esse trabalho se aproximaria das ideias do autor russo. Porém, quando há um movimento de distanciamento/ refração em relação a essas ideias, prefere-se o termo "gêneros textuais". No caso do Brasil, trabalhos que se utilizam desta terminologia estão mais vinculados à proposta dos PCN e dos autores de Genebra comentados acima e objetivam, por exemplo, pesquisar os aspectos micro e macroestruturais que entram na constituição do texto, buscando muito mais descrever o modo como um gênero se estrutura do que as implicações sociais e ideológicas de sua produção. Compreendemos a complexidade que Bezerra (2017) confia ao gênero, utilizando-se da ideia de que esse objeto de estudos, "holístico" 
por constituição, como ele menciona, não deveria ser submetido a dicotomias como "textual x discursivo". No entanto, não assumimos aqui uma dicotomia, mas uma “diferenciação". Por isso, não colocamos o textual versus, mas “ou” discursivo. Isso sim: trata de uma questão de escolha de ponto de vista sobre o objeto. É da ordem das limitações, das bordas, do desenho típico de qualquer pesquisa científica que não tem a pretensão de conceber seu objeto como totalizante, ou holístico, como queira.

No caso mais específico da pesquisa sobre ensino de produção textual por meio de gêneros, assumimos a "diferenciação" exposta no parágrafo anterior como norteadora de escolhas teórico-metodológicas que geram resultados distintos quando ancoradas na noção de gênero de "texto" ou gênero do "discurso". E isso, para nós, não é um entrave no tratamento dado ao objeto de estudo, como quer Bezerra (2017), mas, antes, reiteramos, se constitui como próprio do fazer científico, que prima pela modéstia em reconhecer limites e alcances de sua perspectiva. Enfim, a ideia de "gêneros textuais", predominante nos estudos brasileiros sobre ensino de língua materna, por tomar as categorias textuais como fundamentais na análise de gêneros, faz emergir certos problemas conceituais que precisam, necessariamente, de definições precisas por quem opta por essa linha em sua pesquisa. Citamos alguns:

- A necessária e difícil conceituação de termos como "texto", "gênero", "sequência textual", "tipologia textual" e "suporte";

- A complexa questão do agrupamento de gêneros, conforme os aspectos tipológicos do argumentar, expor, descrever ações etc., e sua consequente escolha sobre qual deles trabalhar em sala. Embora os proponentes desse agrupamento - estudiosos de Genebra - reforcem o fato de que estes sejam tipos em número finito que regulam em certo sentido a constituição dos gêneros, em número infinito, não há consenso entre os estudiosos na quantidade de tipos existentes nem na terminologia usada. Além disso, não é incomum surgirem gêneros que, para distintos pesquisadores, podem 
pertencer a um ou outro agrupamento tipológico, gerando muitas confusões quando tais gêneros são "transpostos” para o espaço didático.

Para quem opta pela linha dos "gêneros discursivos", conceituar ou diferenciar essas terminologias não são uma preocupação imperiosa, talvez secundária, uma vez que nessa linha os gêneros relacionam-se aos aspectos sociais, da esfera de circulação, como dissemos antes, e não se confundem com uma tipologia textual ou outra.

\section{Das escolhas metodológicas}

Um dos pontos mais positivos que percebemos ao investigarmos os artigos referese ao fato de que os gêneros abordados pelos pesquisadores são os mais variados possíveis por pertencerem a diferentes esferas de circulação humana: artigo de opinião, carta de leitor, entrevista, diário de bordo, carta-denúncia, resumo, relato de viagem, poesia, esquete, crônica, seminário etc.

Quanto às escolhas relativas ao tipo de pesquisa, ou caminhos metodológicos adotados, observamos também uma variedade de procedimentos que vão desde análises documentais até pesquisas-ação. Na tabela abaixo é possível verificar essa variedade. Utilizamos a mesma terminologia empregada pelos articulistas com alguns ajustes feitos por nós quando o autor do artigo não esclarecia ou não deixava explícito seu tipo de pesquisa:

Tabela 3. Principais procedimentos metodológicos usados na análise de produções textuais por meio de gêneros no contexto didático

\begin{tabular}{|c|c|c|c|c|c|}
\hline $\begin{array}{l}\text { Tipos de pesquisa \edição } \\
\text { SIELP }\end{array}$ & 2011 & 2012 & 2014 & 2016 & Total \\
\hline $\begin{array}{l}\text { Pesquisa de campo: análise de } \\
\text { texto de aluno (pesquisador } \\
\text { apenas coletou) }\end{array}$ & 1 & 0 & 0 & 3 & $4-9,5 \%$ \\
\hline $\begin{array}{l}\text { Pesquisa de campo: análise de } \\
\text { relatos de experiências/ planos } \\
\text { de aula de professores }\end{array}$ & 0 & 1 & 1 & 1 & $3-7 \%$ \\
\hline $\begin{array}{l}\text { Pesquisa de campo: observa- } \\
\text { ção não-participante (pesqui- } \\
\text { sador em sala sem interferir) }\end{array}$ & 0 & 1 & 1 & 0 & $2-5 \%$ \\
\hline
\end{tabular}




\begin{tabular}{lccccc}
\hline $\begin{array}{l}\text { Pesquisa documental: análise } \\
\text { de LD }\end{array}$ & 0 & 3 & 4 & 0 & $7-17 \%$ \\
$\begin{array}{l}\text { Pesquisa-ação: pesquisador } \\
\text { forma professores para aplica- } \\
\text { ção de proposta }\end{array}$ & 0 & 2 & 0 & 1 & $3-7 \%$ \\
$\begin{array}{l}\text { Pesquisa-ação: pesquisador } \\
\text { aplica proposta a alunos }\end{array}$ & 0 & 6 & 7 & 10 & $23-54,5 \%$ \\
\hline
\end{tabular}

Fonte: os autores.

Os dados mostram que, apesar da variedade de escolhas metodológicas efetuadas nas pesquisas sobre o assunto aqui tratado, elas se concentram basicamente em dois eixos: na análise documental de livros didáticos de língua portuguesa e na pesquisa-ação, com clara ênfase dada a este último recurso metodológico. Por essa razão, dedicaremos o item a seguir apenas para tecer observações sobre esta escolha, detendo-nos, neste momento, a algumas observações sobre os demais caminhos adotados pelos pesquisadores:

I. O primeiro aspecto que nos chama a atenção refere-se à pouca expressividade de pesquisas de campo em que o investigador, ao ir à escola, atua apenas como observador não-participante da aula ou apenas coleta com professores relatos de experiências e planos de aulas destes ou produção textuais escritas já trabalhadas com os alunos;

II. Esse primeiro elemento destacado explica, em certo sentido, o segundo tipo de pesquisa mais utilizado pelos estudiosos: a análise documental de livros didáticos. Isso, porque, ao irem à escola, os pesquisadores preferem realizar intervenções mais pontuais no processo de aprendizagem de alunos em sala de aula, as chamadas pesquisas-ação, como se percebe na tabela acima, do que apenas realizar observações não-participantes. Assim, quando não tomam o chão da escola como lugar de investigação, debruçam-se sobre livros didáticos. Estes, por serem instrumentos de absorção direta das políticas curriculares nacionais e por estabelecerem uma ponte entre essas políticas e as práticas didáticas, já que são adotados nas escolas, tornam-se importantes documentos de análise científica. De todo modo, 
a opção predominante sobre investigação no interior do espaço escolar parece ser uma escolha interessante quando pensamos nas prementes demandas sociais por uma pesquisa mais engajada com as ditas "reais" práticas de aprendizagem dos alunos. Mas em que termos essas pesquisasação têm sido efetuadas em sala de aula? Corresponderiam a essas demandas por transformação dos processos de ensino-aprendizagem de língua materna? Cremos, ainda, que, sob o manto dessas questões, há uma pergunta emergente: "Como a pesquisa linguística pode contribuir com transformações efetivas nos processos de ensino-aprendizagem da língua portuguesa?" São problemas abrangentes, que têm batido à porta da ciência linguística, convocando-nos a uma tomada de posição sobre o tema. E, embora seja este ainda um incipiente estudo sobre complexos problemas, não podemos nos furtar a algumas observações feitas no item a seguir que podem - e devem - ser retomadas mais cautelosamente em trabalhos posteriores.

Algumas problematizações sobre o uso da "pesquisa-ação" como principal instrumento de pesquisa sobre ensino de produção textual hoje

De que trata, afinal, a famigerada pesquisa-ação? Gil (2012) vai dizer que é o tipo de pesquisa que confronta as tendências clássicas que, ilusoriamente, concebem o fazer científico como neutro, imparcial. Desse modo, os modelos empíricos clássicos de coleta de dados, para o autor, e com base em filósofos como Jürgen Habermas, são, muitas vezes, formas de controle social, com intuito de modelar comportamentos. É nesse debate, portanto, que a pesquisa-ação se insere como forma de "possibilitar a obtenção de resultados socialmente relevantes" (GIL, 2012, p. 30).

Diante disso, faz todo o sentido a opção predominante dos linguistas, como vimos na Tabela 3, quando se embrenham pelos labirintos do ensino de produção de textos por meio de gêneros na escola. Como atividade processual, construtiva e essencialmente ligada 
a um fazer social, e por isso, crítico e reflexivo, a produção de textos orais e escritos exige uma compreensão nada superficial dos mecanismos socioculturais que delimitam "onde", "como", "por que" razões e "para quem" endereçamos nossos textos. Além disso, a própria ideia de gênero, como mostra Bakhtin (2016), não admite, quando se tem como tarefa a compreensão de um gênero discursivo, um mero exercício de reconhecimento e classificação de elementos linguístico-textuais. Há, portanto, uma íntima relação entre a pesquisa sobre gêneros, ensino de língua e pesquisa-ação. Mas os pesquisadores estariam utilizandose do instrumental oferecido pela pesquisa-ação para intervir de modo significativo no espaço didático ou têm se embrenhado por esses labirintos quase às cegas, desconsiderando o potencial desse instrumental?

Antes de responder a essa pergunta, é preciso expor aqui ao menos os princípios indispensáveis que definem uma pesquisa-ação. Barbier (2004), por exemplo, esclarece que o movimento operado por uma pesquisa-ação visa essencialmente a alguma "mudança" de prática social. Entretanto, essa mudança só é possível no bojo de um “processo” complexo de observação e ação empreendida pelos participantes. É, portanto, nesse processo que o objeto de pesquisa ganha contornos específicos e convoca os sujeitos à investigação:

Ora, é somente durante o processo de pesquisa que o verdadeiro objeto (a necessidade, o pedido, os problemas) emerge, e que os participantes são capazes de apreendê-lo progressivamente, de nomeá-lo e de compreendê-lo. (BRABIER, 2004, p. 51)

Na mesma linha de conceituação, Thiollent (2011) ainda apresenta uma importante faceta da pesquisa-ação, que considera, necessariamente, a relação dialógica, e, por isso, dialética e construtiva, entre todos os envolvidos:

Quando se trata de uma ação de caráter cultural, educacional ou político, os pesquisadores e participantes devem estar em condição de fazer uma avaliação realista dos objetivos e dos efeitos e não ficarem satisfeitos ao nível das declarações de intenção (como muitas vezes ocorre). O desenrolar e a avaliação de ação cultural são talvez mais 
difusos e menos evidentes do que no caso de atos técnicos bem definidos. (THIOLLENT, 2011, p. 50).

Planejamento, intervenção e avaliação (auto)crítica dos resultados com atenção a importantes doses de elementos-surpresa que possam surgir para se avançar ou recuar são momentos comuns e necessários desse tipo de pesquisa. Por isso, é um processo em espiral de retomada e progresso, a depender das circunstâncias, e não da vontade soberana dos pesquisadores. Ainda na constituição do campo semântico que delineia esse tipo de pesquisa, aparecem termos como “escuta sensível”, em que a voz dos participantes, em diálogo com a voz dos investigadores, ganha relevo. Podemos sumarizar da seguinte forma as principais características da pesquisa-ação:

I. Parte de um intenso estudo de base etnográfica do lugar de investigação aspectos socioculturais e históricos -, tendo em mãos um planejamento que pressupõe uma ampla escuta dos participantes do local;

II. Grande conhecimento do objeto a ser investigado para, a partir dos dados obtidos na investigação do local e das necessidades dos participantes, elaborar projetos interventivos que visem à transformação das práticas;

III. Acompanhamento intenso - longitudinal - de cada processo do projeto interventivo, utilizando-se, para isso, de gêneros e suportes diversos para registro, como diários de bordo e gravações audiovisuais, a fim de se elencarem os aspectos frágeis das ações interventivas para uma revisão ou mesmo abandono de certos caminhos;

IV. Realização de debates e diagnósticos a fim de se verificarem quais mudanças podem estar em curso ou mesmo já possam ter sido acomodadas na comunidade em questão.

Esses pontos nos dão ideia do alcance de uma pesquisa que tem como objetivo primordial a mudança social crítica de uma comunidade. E o que observamos ao lermos especialmente os artigos dos anais do SIELP que tratam dessa modalidade de pesquisa aplicada a alunos em processo de aprendizagem da produção textual é que há equívocos na 
concepção desse rico instrumento metodológico. Assim, olhando os quatro itens acima, elencamos a seguir os aspectos mais problemáticos que nos chamaram a atenção quando os pesquisadores intentaram propor e aplicar projetos de produção textual por meio de gêneros nas escolas brasileiras, utilizando-se dessa modalidade de pesquisa:

I. Em relação ao item I, o processo de produção textual, por ser uma atividade constitutivamente social, dialógica, heterodiscursiva (cf. BAKHTIN, 2015), necessariamente precisa considerar o aluno como "efetivo produtor de seus textos", autor, como bem mostrado por Geraldi (1991). A escuta ou a leitura dos textos dos alunos, nesse caso, pressupõe não apenas a elaboração de atividades de reescrita, mesmo que nestas o professor busque explicitar com detalhes os ditos problemas considerados na construção do gênero pelo aluno. Antes, a reescrita ressignifica-se nesse processo dialógico de negociação de significantes e significados textuais do professor com o aluno. Algumas propostas dos artigos analisados, em certo sentido, apresentam um cuidado em relação à reescrita dos alunos, propondo bilhetes que objetivam abrir o diálogo, revendo a postura arcaica que apenas separa o "certo" do "errado". Todavia, se olharmos para as exigências postas por uma pesquisa-ação eficaz, ao final do processo da pesquisa em si, faz-se necessário um retorno aos alunos para a exposição dos resultados e realização de debates sobre efetivas mudanças que possam ou não ter ocorrido em suas produções. Mas isso não é evidenciado em nenhum dos artigos analisados;

II. Em II, e de certo modo em IV, a investigação do local inclui um mapeamento de aspectos etnográficos da comunidade em questão. No caso da pesquisa-ação com alunos, levam-se em conta aspectos culturais, socioeconômicos desses participantes, problemas de aprendizagem verificados em avaliações regionais e nacionais, concepção dos projetos político-pedagógicos desenvolvidos no local etc. Obviamente, a depender do recorte 
de pesquisa, alguns elementos podem ser mais ou menos presentes, ou mesmo ausentes, mas um mapeamento bem desenhado e justificado é necessário para orientar nas escolhas do pesquisador e nos resultados obtidos. Ou seja, a pesquisa-ação não nega o papel investigativo e analista do pesquisador, mas rejeita posturas que olham, por exemplo, para o texto produzido pelo aluno sem ancorá-lo a fatores como os citados. Como, afinal, pesquisa-se a produção textual, especialmente aquela fundamentada na teoria dos gêneros discursivos, se se desconsideram que tal produção é feita por um sujeito-aluno, situado histórica e socialmente e sob pressões de projetos políticos e pedagógicos da escola onde circula? Isso seria o mesmo que negar a intrínseca relação da esfera com seus estruturantes discursivos, os gêneros. De qualquer forma, não verificamos em nenhum dos artigos produzidos um mapeamento desse tipo.

III. Talvez o item III seja o que mais apresenta equívocos nos trabalhos analisados nos anais do SIELP. A pesquisa-ação, quanto ao tempo de duração, é relativa principalmente porque, por seus movimentos em espiral, pode prescindir ou não de mais atenção a determinadas ações efetuadas. Isso não significa que o pesquisador não consiga prever o tempo de sua pesquisa, e deve fazê-lo, mas precisa planejar sua investigação tendo em vista um tempo "médio", e não um tempo preciso, inflexível. Nesse sentido, é que falamos em pesquisa "longitudinal", não significando necessariamente um longo período, mas, para usar um termo bakhtiniano, um período que compreenda um "acabamento" possível após constantes movimentos dialógicos em que a "responsividade", entendida como "ato responsável”, seja um constituinte primordial do processo. E, certamente, a produção de textos é uma atividade que, em sua constituição processual, exige esse cuidado. Nos trabalhos analisados, a maioria das ditas pesqui- 
sas-ação se apoiaram nas "sequências didáticas", como proposto pelos autores de Genebra, a fim de sequenciar o tempo de aprendizagem, firmado sobretudo na realização de uma "produção inicial" com alguns "módulos de atividades" para se chegar a uma "produção final". O problema maior é que, seguindo a ideia desses autores, os estudos que verificamos nos anais já delimitam previamente, antes mesmo de ir à escola, o tempo de intervenção nas salas de aula, geralmente com duração máxima de dois meses. Mas seria possível investigar um processo tão complexo como a produção textual em um período de tempo inflexível como esse? Talvez até sim, no entanto, aliado a esse problema está o modo como tem se buscado realizar as intervenções: na maioria das vezes, o pesquisador "suspende" um dado período do processo de aprendizagem de algum professor para aplicar sua pesquisa o que, como dissemos, pode significar muito mais uma vontade de modelar comportamentos e modos de conceber a produção textual do que empreender de fato mudanças no processo de ensinar e aprender a produzir textos. Isso porque, ao suspender as aulas que vinham sendo realizadas pelo professor-regente da turma em questão, o pesquisador cria uma espécie de realidade paralela, quimérica, "idealizada unilateralmente". Mesmo quando verificamos aqueles trabalhos de formação de professores em que estes deveriam utilizar os gêneros estudados no processo de formação para levar seus alunos a produzirem textos, ficou claro que esses professores o faziam desconectados de todo o processo de aprendizagem que vinha sendo realizado. Assim, mesmo diante de muitos relatos de pesquisadores eufóricos com os possíveis resultados positivos, questionamos se houve, no dizer piagetiano, além da simples "assimilação" momentânea, uma real "acomodação" de um gênero discursivo, apre(e)ndido de fato, no repertório discursivo dos alunos e, quem sabe, no próprio cotidiano da escola. Enfim, quando muito, essas 
pesquisas parecem apresentar interessantes propostas de aplicação em sala, mas, de igual modo, questionáveis, uma vez que foram concebidas não emergindo da esfera escolar, mas das vontades parciais de seus idealizadores.

\section{Considerações finais}

Como mostramos acima, não é difícil perceber o quanto a teoria de gêneros discursivos tem ganhado espaço na esfera escolar desde os PCN por um motivo bem plausível e, por que não dizer, lógico: busca atender a uma demanda contemporânea da educação em geral, e linguística, em nosso caso, opondo-se frontalmente à perspectiva tradicional que via - e em muitos casos ainda vê - a escola como espaço de formação para o mercado de trabalho em uma lógica capitalista, bancária (cf. FREIRE, 2013), de ensino. Nesse contexto tradicional e reducionista, produzir textos, sobretudo por meio de gêneros discursivos, não seria/é uma atividade bem-vinda, uma vez que exige "tempo" e atenção mais ao "processo" que ao ponto de partida ou de chegada, isto é, ao "produto". E, no capitalismo, produtividade em larga escala suscita frases de efeito valiosas como "tempo é dinheiro!".

Por isso, é urgente incentivar teorias e métodos variados, especialmente aqueles que olham para o objeto de estudos com as lentes do "social", passível de possibilitar a "construção de conhecimentos" e não a tendenciosa "fabricação" de comportamentos. No entanto, como vimos, há muito o que se fazer, especialmente neste momento em que nossos pesquisadores em linguística/ ensino de língua portuguesa têm se embrenhado por novas possibilidades metodológicas e, em muitos casos, por não fazerem uso de forma atenta e adequada desses instrumentos, correm o risco de se recalcarem os aspectos críticos e transformadores tão caros aos gêneros discursivos. 


\section{PROBLEMATIZING LINGUISTICS RESEARCH ON THE TEACHING OF TEXTUAL PRODUCTION THROUGH GENRES}

ABSTRACT: This article aims to analyze the main theoretical and methodological choices made by researchers of Brazilian linguistics, especially those interested in the teaching of oral and written textual production that chooses discursive genres as their central object. For this, we collected and analyzed all articles on this theme published in the proceedings of the International Symposium of Portuguese Language Teaching - SIELP - in its Brazilian editions. Although there are efforts to recognize the idea of discursive genres in the school sphere as an effective object of student insertion in social practices to meet contemporary demands, there are many confusions and problems related mainly to the methodological choices made.

KEYWORDS: Linguistic research; Discursive genres; Teaching of textual production; Brazilian Basic Education.

\section{REFERÊNCIAS}

BAKHTIN, Mikhail. Teoria do romance 1: a estilística. Tradução de Paulo Bezerra. São Paulo: Editora 34, 2015.

2016.

. Os gêneros do discurso. Trad. Do russo de Paulo Bezerra. São Paulo: Editora 34,

BARBIER, René. A pesquisa-ação. Tradução de Lucie Didio. Brasília: Liber Livro Editora, 2004.

BATISTA, Luiz E. M. A concepção de prática social por meio da apropriação de gêneros discursivos em documentos nacionais: dos PCN à BNCC. Revista Leia Escola, Campina Grande, v. 18, n. 3, 2018, p. $109-126$.

BAWARSHI, Anis S.; REIFF, Mary Jo. Gênero: história, teoria, pesquisa, ensino. Tradução de Benedito Gomes Bezerra. São Paulo: Parábola, 2013.

BEZERRA, Benedito G. Gêneros no contexto brasileiro: questões [meta]teóricas e conceituais. São Paulo: Parábola, 2017.

BRASIL. Secretaria de Ensino Fundamental. Parâmetros Curriculares Nacionais de Lingua Portuguesa: terceiro e quarto ciclos do ensino fundamental. Brasília, DF: MEC, 1998.

BRASIL. Ministério de Estado da Educação. Base nacional comum curricular, Brasília, DF: MEC, 2017.

FREIRE, Paulo. Pedagogia do oprimido. 60 ed. São Paulo: Paz e Terra, 2013.

GERALDI, João W. Portos de passagem. São Paulo: Martins Fontes, 1991.

GIL, Antônio C. Métodos e técnicas de pesquisa social. São Paulo: Atlas, 2012. 
ROJO, Roxane. Gêneros discursivos e gêneros textuais: questões teóricas e aplicadas. In: MEURER, J. L.; BONINI, A.; MOTTA-ROTH (Org.). Gêneros: teorias, métodos, debates. São Paulo: Parábola, 2005.

THIOLLENT, Michel. Metodologia da pesquisa-ação. 16 ed. São Paulo: Cortez, 2011.

Recebido em: 30/08/2019.

Aprovado em: 30/10/2019. 